\title{
Time Line of Important Events
}

Circa 1983 - Rosa and Lucho move permanently to Cuenca from Cumbe

Late 1987-Rosa's brother Carlos migrates to New York

December 1988 - Ann arrives in Cuenca from Guayaquil

February 1989-Ann meets Rosa and her family

September 1989-Rosa and Lucho baptize their four youngest children; Ann becomes Alexandra's godmother

December 1989-Ann leaves Cuenca

Circa January i99I - Rosa's brother Miguel migrates to New York

Circa December 1992 - Rosa and Lucho purchase a taxi

June 1993 - Rosa and Lucho's youngest son, Billy, is born

June 1993 - Ann returns to Cuenca for two months to study ethnomedicine

June 1995 - Ann (with Rich and Isabel) returns to Cuenca for two months to study natural medicine stores

June 1995 - Billy is baptized; Rich and Ann become his godparents

October 1995 - Vicente migrates to New York

July i997-Ann visits Cuenca for two weeks

May 1999 - Ann and Rich visit Vicente on Staten Island before going to Ecuador for two months to interview the family about transnational migration

August 2000-Ann visits Vicente in New York

October 2000 - Lucho arrives in New York 
THIS PAGE INTENTIONALLY LEFT BLANK 
From Cuenca to Queens 


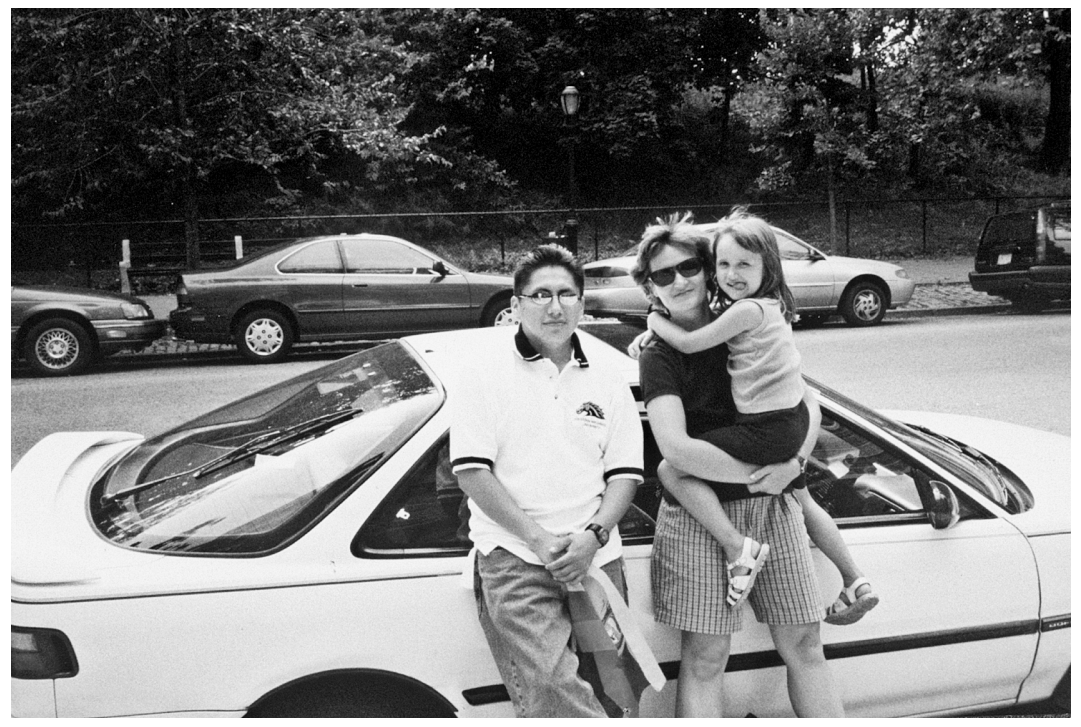

1.1. Vicente, the author, and her daughter, Isabel, in New York in August 2000. We are leaning against Vicente's car. Note the Ecuadorian flag in his hands. 